\title{
Integralidade do cuidado na saúde: indicações a partir da formação do enfermeiro*
}

COMPREHENSIVE HEALTH CARE: INDICATIONS FROM THE TRAINING OF NURSES

INTEGRALIDAD DEL CUIDADO EN LA SALUD: INDICACIONES DESDE LA FORMACIÓN DEL ENFERMERO

\author{
Kênia Lara Silva', Roseni Rosângela de Sena²
}

\section{RESUMO}

O estudo tem como objetivo compreender a formação do enfermeiro para a integralidade do cuidado. Utilizaram-se como fontes de dados entrevistas com docentes, estudantes e enfermeiros de serviços, submetidas à análise de discurso. Foi reconhecida a compreensão da integralidade do cuidado na perspectiva de um modelo de atenção à saúde que tem como direcionalidade o cuidado centrado no usuário. Suscitaram reflexões sobre as tecnologias e a forma de organização do trabalho, expressas por uma tensão permanente: Clínica versus Saúde Coletiva, como desafio para a integralidade do cuidado. Identificou-se que construir a integralidade na formação implica assumir o agir em saúde como princípio educativo em uma nova forma de aprender-ensinar em saúde, que rompe com o saber formatado e descontextualizado. Concluiuse que a integralidade é tomada como objeto de reflexão no movimento de mudança nas práticas pedagógicas e que reflete na atenção à saúde.

\section{DESCRITORES}

Atenção integral à saúde.

Educação em enfermagem.

Atenção à Saúde.

\begin{abstract}
This study has the objective of understanding the training of nurses for comprehensive health care. It used data from interviews with teachers, students and service nurses submitted to discourse analysis. There is an understanding of comprehensive care in the training of nurses from the perspective of establishing a healthcare model in which care is directed to the patient. There are reflections regarding the technologies and the form of organization of the work, expressed in a permanent tension: Clinical versus Collective Health as a challenge for comprehensive care. It was identified that building completeness in the formation implies assuming acting in health as an educative principle in a new form of learning-teaching in health, which breaks up with pre-formed, out-of-context knowledge. The conclusion is that comprehensive health care is taken as an object of reflection in the movement for change in the pedagogical practices, and that it is reflected in health attention.
\end{abstract}

\section{KEY WORDS}

Comprehensive health care.

Education, nursing.

Health Care.

\section{RESUMEN}

El estudio tiene como objetivo entender la formación de las enfermeras para el cuidado integral. Los datos fueron obtenidos de entrevistas con profesores, estudiantes y enfermeras del servicio sometidos a análisis de discurso. Fue reconocida la comprensión de la integralidad del cuidado en la perspectiva de un modelo de atención a la salud que tiene como orientación el cuidado centrado en el usuario. Suscitaron reflexiones sobre las tecnologías y la forma de organización del trabajo, expresadas por una tensión permanente: Clínica versus Salud Colectiva, como desafío para la integralidad del cuidado. Se identificó que construir la integralidad en la formación implica asumir el actuar en salud como principio educativo en una nueva forma de aprender-enseñar en salud, que rompe con el saber formateado y descontextualizado. Se concluye que la integralidad se toma como objeto de reflexión en el movimiento de cambio en las prácticas pedagógicas y que se refleja en la atención a la salud.

\section{DESCRIPTORES}

Atención integral de salud. Educación en enfermería. Atención a la Salud.

\footnotetext{
* Extraído da dissertação "Movimento de mudança da educação de enfermagem: construindo a integralidade do cuidado na saúde", Escola de Enfermagem, Universidade Federal de Minas Gerais, 2005. ${ }^{1}$ Enfermeira. Doutoranda de enfermagem da Escola de Enfermagem, Universidade Federal de Minas Gerais (UFMG). Professora Assistente da Pontifícia Universidade Católica de Minas Gerais (PUCMG). Belo Horizonte, MG, Brasil. kenialara17@yahoo.com.br 2 Enfermeira. Doutora em Enfermagem. Professora Emérita da Escola de Enfermagem, Universidade Federal de Minas Gerais (UFMG). Belo Horizonte, MG, Brasil.rosenisena@uol.com.br
} 


\section{INTRODUÇÃO}

O início do século XXI, no Brasil, é marcado pelo movimento de construção de novos paradigmas do processo saúde-doença com repercussões na organização dos serviços de saúde, nas concepções de promoção à saúde, prevenção de agravos e tratamento, fruto da consolidação do Sistema Único de Saúde (SUS). As mudanças de paradigmas e na organização tecnoassistencial em saúde incidem, também, no modelo de formação dos profissionais de saúde, inclusive os de enfermagem.

As escolas de ensino superior avançaram na con-cepção crítico-reflexiva em relação à sociedade, mas revelam-se conservadoras na maneira como ensinam e operam os conteúdos, adotando grades curriculares estanques, que levam à formação de um estudante comparável a uma colcha de retalhos, por somatória ou justaposição de conhecimentos ${ }^{(1)}$. O que prevalece e orienta a construção dos Projetos Político-Pedagógicos - PPP, na maioria das escolas, é a ênfase na concepção do processo saúde-doença, limitando-se tais projetos a abordar a enfermidade, a cura e a atenção individual, que não capacita os estudantes para mobilizar os saberes na busca da integralidade ${ }^{(2)}$.

Em 2001, as Diretrizes Curriculares do Curso de Graduação em Enfermagem (DCN) foram aprovadas pelo Ministério da Educação, estabelecendo as competências e habilidades a serem desenvolvidas no processo de formação do enfermeiro ${ }^{(3)}$. A implantação das DCN tem sido assumida como estratégia potente para redirecionar a formação dos profissionais de enfermagem, estabelecendo um marco estruturante na construção de um novo paradigma para a educação de enfermagem: a orientação da formação para impulsionar a efetivação dos princípios do SUS e das demandas e necessidades de saúde da população(4-5).

Percebe-se, assim, nas Escolas, um terreno de disputas entre projetos hegemônicos que determinam a organização curricular centrada no conhecimento e na transmissão e a configuração de um movimento contrahegemônico representado pelas proposições das Diretrizes Curriculares Nacionais. Essa tensão foi tomada como objeto de estudo da dissertação Movimento de Mudança na Educação de Enfermagem: construindo a integralidade do cuidado na saúde, da qual se apresenta, neste artigo, um recorte dos resultados. Propôs-se a compreender a orientação da formação do enfermeiro para a integralidade da atenção à saúde, entendendo a abordagem da integralidade como referencial político-pedagógico na formação e como premissa para um novo modo de ensinar, aprender e cuidar em saúde ${ }^{(2)}$.

A mudança na formação do enfermeiro requer a atuação em coletivos capazes de incidir sobre as políticas públicas que permitam superar os desafios e criar oportunidades de melhoria na qualidade do ensino. Dentre os pressupostos defendidos na formação do enfermeiro, destaca-se a orientação da formação para reconhecer a saúde como direito, determinada pelas condições dignas de vida, atuando de forma a garantir a integralidade da assistência ${ }^{(3)}$.

A integralidade na atenção à saúde é definida como um princípio do SUS, orientando políticas e ações programáticas que respondam às demandas e necessidades da população no acesso à rede de cuidados em saúde, considerando a complexidade e as especificidades de diferentes abordagens do processo saúde-doença e nas distintas dimensões, biológica, cultural e social do ser cuidado.

A integralidade se constrói na práxis do conjunto dos profissionais dos serviços de saúde e nas diferentes formas de encontro desses profissionais com e no serviço(6). A prática de enfermagem, inserida no contexto das práticas em saúde, enfrenta o desafio cotidiano de imprimir uma nova lógica à organização do trabalho, configurando um agir pautado na integralidade e, neste sentido, a formação dos enfermeiros também se apresenta como um campo em que a integralidade é premissa para a reorganização das práticas, uma vez que determinada a aquisição de competências e habilidades para a prática profissional.

Ao considerar que a integralidade constitui-se no cotidiano do trabalho, por meio das interações que se estabelecem, é preciso analisar como o cotidiano do trabalho em saúde é incorporado na formação dos profissionais e como a formação dos profissionais reflete e transforma o dia-a-dia do trabalho em saúde.

\section{MÉTODO}

Trata-se de um estudo de caso, de abordagem qualitativa, aportado na dialética como referencial teórico-filosófico. O trabalho de campo foi realizado após aprovação do projeto no Comitê de Ética e Pesquisa da Universidade Federal de Minas Gerais (Parecer n. 351/04) atendendo as exigências da Resolução 196/96 do Conselho Nacional de Ética em Pesquisa.

O cenário do estudo foi a Escola de Enfermagem da Universidade Federal de Minas Gerais (EEUFMG), tendo em vista a história da instituição na formação de enfermeiros, seu caráter de instituição pública comprometida com os ideários do Movimento de Reforma Sanitária e do Sistema Único de Saúde, os referenciais presentes em seu PPP e o momento vivenciado por essa instituição quanto às discussões acerca de mudança curricular e de implantação das DCN. Assim, analisar o processo de formação 
do enfermeiro, nesse cenário, em um momento singular da instituição, contribuiu para as reflexões acerca da proposta de mudanças no ensino de graduação para afirmação dos princípios do SUS, especialmente a integralidade da atenção.

Os participantes deste estudo foram atores do processo ensino-aprendizagem em enfermagem: seis estudantes, oito docentes e três enfermeiros de serviço. Por se tratar de um estudo qualitativo, não foi intenção preocupar-se com a quantificação dos participantes, mas com sua representatividade. O número de participantes do estudo foi determinado durante o trabalho de campo, mediante a avaliação do pesquisador, após julgar esclarecido o assunto em foco.

A seleção dos docentes para a coleta de dados foi realizada aplicando-se os seguintes critérios de inclusão: que o docente compusesse o quadro permanente da instituição, atuando há mais de 4 anos e que, no mínimo, 1 docente de cada período participasse da coleta de dados.

A abordagem dos estudantes foi realizada, ocasionalmente, procurando-se investigar o período do curso que freqüentavam e o interesse em participarem do estudo. Participaram como informantes 6 estudantes, sendo 2 do ciclo básico ( 1 e e 2 o períodos) e 4 do ciclo profissional (5으, 7으, 8으 e 9 ㅇ períodos).

A inclusão dos enfermeiros que atuam em serviços utilizados como cenários de aprendizagem, justificou-se por entender que a busca da integralidade na atenção à saúde deve ser contemplada no movimento de articulação ensino-serviço, teoria-prática e ação-reflexão-ação. A indicação dos enfermeiros dos serviços para a participação na coleta de dados foi feita pelos docentes seguindo os critérios de que o cenário de aprendizagem seja utilizado pela EEUFMG há, no mínimo, 2 períodos e/ou que o enfermeiro tenha acompanhado a prática dos estudantes durante, no mínimo, 2 semestres. Optou-se por incluir os enfermeiros que acompanham os estudantes nos estágios curriculares do 8ㅇ e do 9 períodos, pois nos estágios dos outros períodos a supervisão não é feita diretamente pelo enfermeiro do serviço. Foram incluídos, então, três enfermeiros, sendo dois da rede básica de serviços de saúde e um da área hospitalar, para garantir a diversidade de significados dos profissionais que atuam em serviços distintos da rede de cuidados em saúde.

O instrumento utilizado para a coleta de dados foi a entrevista individual com roteiro semi-estruturado. As entrevistas foram gravadas após a anuência dos participantes e a assinatura do Termo de Consentimento Livre e Esclarecido que informava os objetivos e as finalidades do estudo e o compromisso de anonimato e o uso dos dados para a produção técnico-científica. Os dados obtidos foram submetidos à análise de discurso na perspectiva da abordagem hermenêutica-dialética(7).
A análise consistiu num movimento de três etapas: organização do material empírico com transcrição e disposição dos discursos em quadros; leituras exaustivas dos discursos para apreender as idéias centrais e, após o estabelecimento das idéias centrais, leitura vertical atravessando as respostas de cada participante e, horizontal, confrontando os diferentes participantes por idéias centrais. A aproximação das Idéias centrais semelhantes deu origem aos temas, e do agrupamento dos temas recorrentes emergiram as categorias e sub-categorias empíricas.

Este artigo descreve os resultados da categoria empírica Modelo de atenção à saúde: construindo a integralidade do cuidado cuja essência é a compreensão dos participantes sobre o modelo tecnoassistencial, revelada nos discursos por citações que remetem ao objeto e finalidade do trabalho, traduzidos como um movimento de reconstrução política das práticas em saúde que tem como centralidade o sujeito com suas demandas e necessidades. Ancoram o movimento de reconstrução reflexões sobre as tecnologias e a forma de organização do trabalho, expressas nos discursos, por uma tensão permanente Clínica versus Saúde Coletiva como desafio para a busca da integralidade no cuidado em saúde.

Na apresentação dos resultados, é registrada, em letra estilo itálico, idéias centrais reveladas nos discursos, identificadas com um código composto por uma letra e 2 números, como por exemplo D1-3. A letra D, E ou S representa, respectivamente, o docente, o estudante ou o enfermeiro de serviço participante do estudo e o número que se segue à letra identifica a ordem da realização das entrevistas por segmento (D1 a D8, E1 a E6 e S1 a S3). O número indicado após o hífen representa a ordem da idéia central no discurso daquele participante.

Para a compreensão do objeto de estudo foram utilizados, também, dados documentais fornecidos pela instituição: Projeto Político Pedagógico e Planos de Cursos da EEUFMG; relatórios das oficinas de trabalho, seminários e reuniões da Comissão de Mudança Curricular; Leis, Normas e Portarias que regulamentam as DCN.

Na última etapa da análise, fez-se a interpretação das categorias e sub-categorias empíricas, estabelecendo diálogos com os autores consultados e a experiência e conhecimento da pesquisadora, num verdadeiro movimento dialético, visando ao concreto pensado(7) ${ }^{(7 e v e l a n d o}$ as determinações e as especificidades que se expressam na realidade.

\section{RECONSTRUINDO UM PROJETO POLÍTICO EM BUSCA DA INTEGRALIDADE: RESULTADOS E DISCUSSÃO}

Os resultados do estudo direcionam para a compreensão de que os participantes entendem a integralidade do cuidado como um pressuposto para 
atender às necessidades biopsicossociais, espirituais e emocionais (D6-1; S3-1), inclusive dar atenção a angústias, medos, problemas financeiros e familiares do ser cuidado (E2-1).

Os entrevistados expressam que a integralidade pressupõe a compreensão do sujeito que recebe cuidado na sua individualidade, mas, também,

inserido no contexto familiar, na coletividade e na sociedade e que sofre influências das relações sociais, do trabaIho, do mercado de trabalho e das condições ambientais (D1-6; E3-1).

A saúde-doença é entendida pelos participantes do estudo como resultado das formas de organização social, determinada pela maneira como o ser humano se relaciona com a natureza e os outros seres, revelando a concepção de produção social da saúde, conceito também explícito no PPP da instituição.

Na construção da integralidade do cuidado, a relação dialética entre os enfoques individual e coletivo, apresenta-se como perspectiva no reconhecimento das necessidades e subjetividades individuais e coletivas. Essa premissa aparece nos discursos dos participantes da pesquisa que reconhecem o ser humano biopsicossocial, espiritual como sujeito do cuidado.

$\mathrm{O}$ respeito à pessoa considerando a singularidade, as relações emotivas, a saúde mental, a espiritualidade e a cidadania (D7-3)

é enfatizado pelos participantes da pesquisa como pressuposto na construção da integralidade do cuidado. Essa compreensão parece determinante de um projeto político para a enfermagem brasileira e a assume enquanto práxis de relações, redefinindo fazeres e saberes que incorporem a subjetividade e a singularidade como característica dessa práxis. Singularidade pelo fato de sermos diferentes; subjetividade pelo fato de sermos os outros, ou seja, por nos constituirmos de relações e experiências que são construídas a cada dia ${ }^{(8)}$.

Ao assumirem esse sentido da integralidade, os participantes da pesquisa remetem a uma abordagem nas práticas em saúde que valoriza a dimensão subjetiva e que implica construir um modelo de atenção e de ensino que reconheça o singular sem desprezar o coletivo e que seja centrado na pessoa que recebe o cuidado. Defender a integralidade é, antes de tudo, defender que as práticas em saúde sejam intersubjetivas, ou seja, que levem em consideração as singularidades de cada sujeito e que, a partir da relação dialógica, sejam construídos os projetos terapêuticos individualizados ${ }^{(6)}$.

É evidenciada, nos discursos dos participantes, a compreensão da integralidade como princípio na assistência às demandas e necessidades de saúde da população, sendo essa a finalidade do trabalho em saúde, revelada pelos participantes da pesquisa.

\section{É importante destacar que}

as necessidades do ser humano não são quaisquer, aparecem como aquilo que precisa necessariamente ser satisfeito para que esse ser continue sendo um ser(9).

As necessidades de saúde não se apresentam de forma casual nos indivíduos, mas constituem-se em carências dos sujeitos, em relação a um tempo e lugar e não se restringem ao intrínseco ${ }^{(10)}$.

Essa compreensão permite ampliar as reflexões de que as necessidades de saúde podem ser apreendidas em quatro conjuntos: ter boas condições de vida, ou seja, considerar as relações com o ambiente e o trabalho, os hábitos pessoais, as relações de classe e gênero na determinação do processo saúde-doença; ter acesso e poder consumir toda tecnologia de saúde capaz de melhorar e prolongar a vida; possibilitar a criação de vínculo afetivos e efetivos entre cada usuário e a equipe e/ou profissional de saúde e possibilitar às pessoas criarem graus de autonomia no seu modo de levar a vida ${ }^{(11)}$.

Identificam-se, nos discursos dos participantes da pesquisa, relatos que remetem à integralidade como compreensão das necessidades físicas, biológicas, sociais, espirituais, emocionais do ser cuidado (D1-3; D4-1; E1-1) e a exigência de se reorganizar o modelo de atenção à saúde para responder a essas necessidades.

É importante advertir, entretanto, quanto ao fato de as necessidades de saúde não se traduzirem em dispositivo de aprofundamento da medicalização, ou seja, da produção e do consumo exagerado de bens e serviços de saú$\mathrm{de}^{(12)}$. É preciso considerar necessidade de saúde não somente aquilo que o ser cuidado demanda e que o profissional ou serviço de saúde pode responder, mas um olhar sobre o significado do cuidado na vida das pessoas. Essa análise remete, portanto, ao reconhecimento do sujeito e de suas potencialidades na construção do seu modo de caminhar pela vida, significando a responsabilização e autonomia do sujeito. São reveladas, nos discursos dos participantes, citações que remetem à responsabilização do sujeito na ampliação da autonomia e da capacidade de intervenção das pessoas sobre suas próprias vidas, ainda que de forma incipiente, o que nos permite afirmar que a medicalização no atendimento às necessidades de saúde ancora expressões dos participantes sobre o atendimento às necessidades de saúde.

Esse parece ser um ponto fundamental quando se analisa a construção da integralidade do cuidado visto que este supõe redefinição de práticas no sentido de se criar vínculos, acolhimento e autonomia que valorizem as subjetividades inerentes ao trabalho em saúde e às necessidades singulares dos sujeitos como ponto de partida para qualquer intervenção, construindo a possibilidade do cuidado centrado no usuário.

Assim, a mudança na graduação sob o eixo da integralidade implica compreender a dimensão amplia- 
da da saúde, a articulação de saberes e práticas multiprofissionais e interdisciplinares e a alteridade com os usuários para a inovação das práticas em todos os cenários de atenção à saúde e da formação profissional.

Em relação aos saberes constitutivos do modelo de atenção, os participantes da pesquisa afirmam que a integralidade sustenta-se num conceito ampliado de saúde e que, para alcançá-la, não bastam os conhecimentos biológicos (D7-1). É preciso avançar incorporando

conhecimentos das culturas das populações, da organização político-econômica e da influência que essas questões exercem sobre o processo saúde-doença (D2-12; D7-7).

É enfatizada nos discursos a necessidade da abordagem dos aspectos sociais, do contexto, das condições de trabalho, remetida ao campo e núcleo de saberes da Saúde Coletiva. A Saúde Coletiva vislumbra o processo saúde-doença-cuidado na perspectiva histórico-social por meio da ação dos distintos sujeitos em suas relações entre si e na sociedade em que vivem e incorpora os determinantes sociais no atendimento das necessidades de saúde como fenômeno coletivo, sendo as necessidades individuais parte das necessidades sociais ${ }^{(13)}$.

Na construção da integralidade no cuidado à saúde é preciso oferecer, em cada caso, a abordagem que melhor atenda às necessidades do sujeito. Nesse sentido, a enfermagem enfrenta, no conjunto das práticas em saúde, o desafio de formar e capacitar profissionais para uma nova forma de produzir serviços de saúde e cuidado com resolutividade e qualidade e que se apropriem adequadamente dos espaços, instrumentos e agentes dos dois campos de saberes, Clínica e Saúde Coletiva, e de outros saberes como a antropologia, a sociologia, a psicologia e que tenha como finalidade a integralidade do cuidado.

Nesse movimento, emerge uma condição fundamental: o cuidado na perspectiva da integralidade pressupõe o reconhecimento das amplas e complexas demandas e necessidades relacionadas à saúde do ser cuidado e a variedade de tecnologias possíveis de serem produzidas e consumidas no processo de trabalho. Incluem-se neste processo as tecnologias leves que envolvem as relações entre os sujeitos, implicando vínculo, acolhimento e gestão; as tecnologias leves-duras que se referem aos saberes estruturados que operam o processo de trabalho, tais como o conhecimento da epidemiologia, do taylorismo, da comunicação social e outros e as tecnologias duras que, por sua vez, englobam os equipamentos tecnológicos, tais como máquinas, normas, estrutura organizacional, entre outros ${ }^{(14)}$.

No trabalho em saúde, as relações que se processam têm ênfase nas tecnologias leves, valorizando a subjetividade das pessoas em momentos de diálogos, auscultas e interpretações; momentos de cumplicidade, nos quais há produção de uma responsabilização dos problemas a se- rem enfrentados; momentos de confiabilidade e esperança, nos quais se produzem relações de vínculo e aceitação ${ }^{(14)}$

Nesse movimento, a criação de vínculos emerge do encontro entre os sujeitos implicados em relações próximas, com sensibilidade à situação do outro, permitindo a constituição de um processo de transferência entre o usuário e o trabalhador de saúde que possa servir á construção da autonomia.

E sentir-se responsável pela vida e pela morte do paciente, dentro de uma dada possibilidade de intervenção nem burocratizada, nem impessoal(15).

Com essa definição de tecnologia, é possível constatar que os participantes da pesquisa relatam a integralidade do cuidado, sustentada em tecnologias leves, ao referenciála com momentos de diálogos e de expressão das subjetividades. Nesse contexto de valorizar as tecnologias, os protocolos utilizados nos serviços constituem-se em ferramentas que orientam as práticas em saúde, mas que não consideram a singularidade de cada sujeito, a imprevisibilidade e o diverso da existência de cada um no encontro assistencial. Assim, é possível analisar que a normalização expressa nos protocolos como o de Hipertensão Arterial, Diabetes mellitus, Tuberculose, entre outros, se sobrepõe a uma ação que considere a criatividade e a prática emancipatória dos trabalhadores em saúde e dos usuários.

Mas a criação de vínculos entre o profissional e o ser cuidado é pouco citada pelos participantes da pesquisa, sendo mais comum nos discursos dos estudantes ao relacionarem a enfermagem com o tocar, estar próximo e se envolver (E5-7).

É importante ressaltar que, entre os entrevistados, somente os enfermeiros de serviço assinalam os valores éticos da profissão como balizadores na construção da integralidade, referenciando a ética, o bom senso e a criatividade (S1-18; S2-5. Há, também, um enunciado expressivo, quando se analisam esses saberes: uma estudante relata a necessidade da competência para o cuidado integral (E5-10).

Ser competente é reordenar a relação trabalho-educação centrada na práxis, potencializando as ações em saúde com o reconhecimento das subjetividades e das questões éticas. Assim, a integralidade torna-se um imperativo ético-político pela defesa da vida com qualidade e que tem centralidade no cuidado a indivíduos, grupos e coletivos num exercício de cidadania. Assim, para a transformação das condições de saúde e vida das populações, a integralidade do cuidado constrói-se na perspectiva de uma educação capaz de oferecer à sociedade profissionais cuja identidade seja carregada de competência técnico-científica e compromisso ético-político engajados na reconstrução social com base nos princípios de cidadania e justiça social(16). 
Essa premissa exige reconstruir novos referenciais para a formação dos profissionais de saúde ancorados na interdisciplinaridade e no trabalho em equipe. 0 trabaIho interdisiciplinar supõe atitude e método que implicam integração de conteúdos, superação de uma concepção fragmentária para uma concepção unitária do conhecimento, superação da dicotomia ensino e pesquisa e ensino e aprendizagem centrada na visão de educação permanente. A adoção do enfoque interdisciplinar na concepção de conhecimento orienta a síntese dos saberes de modo a ver a realidade globalmente e, sobretudo, pela associação dialética entre dimensões polares como teoria e prática, ação e reflexão, generalização e especialização, ensino e avaliação, meios e fins, conteúdos e processos $^{(17)}$.

De modo especial, a interdisciplinaridade apresentase como proposta para reorientação do conhecimento entre as dimensões curativa e preventiva, individual e coletiva. Nessa perspectiva, exige implementar, no ensino, a conceitualização do processo saúde-doença, adotando concepções mais abrangentes de vigilância à saúde, em contraposição à natureza setorial que caracteriza a atuação dos profissionais na área da saúde.

Com esta compreensão, a interdisciplinaridade e a integralidade são princípios complementares e convergentes na construção dos modos de pensar e fazer da educação e da atenção à saúde, visando um agir humanizado, totalizante e que compreenda a completude dos sujeitos e do processo saúde-doença.

Os participantes da pesquisa expressam a integralidade do cuidado na perspectiva da organização dos serviços de saúde com a articulação das ações de promoção, prevenção e cura (D2-2; E6-4) e fazem referência ao conceito expresso na Constituição brasileira de articular ações curativas e preventivas, individuais e coletivas na atenção à saúde.

Evidencia-se, nos discursos, o reconhecimento da integralidade com a reconstrução de novas práticas direcionadas a qualidade de vida, solidariedade, democracia, direito de cidadania, desenvolvimento sócio-econômico, participação social, pressupostos da promoção da saúde. Entretanto, os participantes da pesquisa revelam que a forma de organização dos serviços de saúde assenta-se num processo de trabalho fragmentado e que tem como foco os procedimentos e as ações curativas (D110; D2-5). Confirmam, assim, a reprodução de um modelo sustentado no indivíduo, na doença e no tratamento.

Nos discursos dos participantes da pesquisa, emerge a dicotomia entre Saúde Pública e Atenção Hospitalar como uma condição que marca a fragmentação da atenção à saúde. Na superação dessa dicotomia é preciso pensar a possibilidade de criar dispositivos para organizar os serviços de saúde em uma cadeia de cuidados na qual os diversos serviços sejam co-responsáveis pela integralidade focalizada, ou seja, respondam, em seu es- paço singular, às necessidades do usuário. Mas é necessário considerar que a atenção às demandas e necessidades em saúde nunca será plena em qualquer serviço de saúde singular pois a integralidade é objetivo de rede ${ }^{(11)}$. A rede concebida e organizada com prioridade para a atenção centrada no usuário requer uma nova ordem éticopolítica em saúde.

Os participantes da pesquisa afirmam, ainda, que na Estratégia de Saúde da Família, que poderia representar uma possibilidade de integralidade focalizada, o que prevalece é o atendimento à demanda espontânea e atenção ao sofrimento manifesto do ser cuidado naquilo que ele interpela (D1-2; S1-4). Um exemplo dessa constatação é a poliqueixosa que, no dizer de uma docente, revela muito da falta da integralidade (D1-4).

A atenção ao poliqueixoso é cada vez mais freqüente na assistência à saúde e envolve situações e demandas de natureza psicossocial, com a busca, pelos usuários, de alívio ou cura para os seus sofrimentos. Constata-se que os profissionais de saúde não estão preparados para lidar com questões como essa, o que implica compreender o processo saúde-doença-cuidado para além da dimensão física, incluindo-se as dores decorrentes do medo, da tristeza, das ansiedades, das adversidades da vida ${ }^{(18)}$.

Na realidade há uma dificuldade dos profissionais de saúde em lidar com sofrimentos; preferem lidar com doença, na qual a racionalidade da biomedicina estabelece referência e pontos de intervenção sobre as lesões e disfunções detectadas ${ }^{(19)}$.

Por outro lado, a subsunção da queixa espiritual e psíquica em sintoma clínico revela, também, a valorização pelos profissionais dos serviços de saúde, ao enfoque curativo, o que é reproduzido nas narrativas que as pessoas constroem e trazem para o encontro clínico, ou seja, se são valorizados, nos serviços, os sintomas clínico-fisiológicos, será essa a forma de expressar as necessidades sentidas e valorizadas no cotidiano pelas pessoas.

Os profissionais revelam a dificuldade de mudança nas práticas e na reorganização dos serviços assumido como resposta à demanda dos usuários por consultas e procedimentos médicos. Esse paradoxo resulta da construção imaginária da oferta e da demanda na busca de resolver as necessidades de saúde na Estratégia de Saúde da Família. A demanda por determinado serviço ou cuidado é conseqüência do não-atendimento de certas necessidades por outros serviços e se constrói num processo de subjetivação de um universo simbólico dando significado a determinada ação(20).

Quando lidamos com a organização de serviços, as necessidades de saúde são o aspecto mais importante, pois suscitam os serviços e embasam a configuração geral de sua estrutura, organização e funcionamento, permitindo trabalhar com as demandas das comunidades. As necessidades em saúde representam a busca de algum tipo de 
resposta para as más condições de vida, a procura de um vínculo afetivo com um profissional de saúde, a necessidade de ter maior autonomia no modo de conduzir sua vida.

A demanda é o pedido explícito, a tradução de necessidades mais complexas do usuário. $\mathrm{Na}$ verdade, a demanda em boa medida, são as necessidades modeladas pela oferta que os serviços fazem. A demanda pode ser por consulta médica, consumo de medicamentos, realização de exames (as ofertas mais tradicionalmente percebidas pelos usuários...) as necessidades podem ser bem outras ${ }^{(11)}$.

Entende-se que, ao demandar atenção médica, os usuários expressam a percepção que tem do que é ofertado pelos serviços de saúde (consultas e procedimentos médicos) conformado e cristalizado no modelo assistencial hegemônico. Assim, a poliqueixa é um critério que legitima a entrada do usuário no serviço e, ao mesmo tempo, assinala para o despreparo dos profissionais e da organização dos serviços para responder às demandas que se apresentam.

Duas questões importantes relativas ao modelo de atenção à saúde, apontadas nos discursos dos entrevistados, referem-se à exigência da produtividade e a rotatividade dos profissionais nas Equipes de Saúde da Família (D1-9; S1-9), o que compromete a criação de vínculos entre trabalhador e usuário na construção do cuidado, uma vez que o vínculo remete a torna-se referência.

Os participantes relatam, também, dificuldades para o trabalho em equipe, revelando que as ações são centradas no ato de um profissional que orienta as decisões sobre a doença, representando um desafio para a construção da integralidade, visto que esta representa um movimento de expressão dos núcleos comuns e núcleos específicos de cada profissional na produção do cuidado em saúde.

O trabalho em equipe implica o compartilhamento do planejamento, na organização coletiva do trabalho sustentada na cooperação e colaboração. Essa organização exige uma atuação integralizadora e unificada dos profissionais no gerenciamento e na produção dos atos de saúde, tendo como centralidade as demandas e necessidades da pessoa cuidada. Com essa premissa de ação usuário-centrada, o núcleo cuidador se impõe, diminuindo as relações de dominação entre os profissionais e explorando a cooperação entre os diferentes saberes e o partilhamento decisório ${ }^{(11)}$.

Emerge, nesse caminho, a construção de projetos terapêuticos num exercício de síntese de competências genéricas e específicas de cada profissional na produção do cuidado coletivo em que há a expressão do núcleo cuidador de cada profissional na integralidade do cuidado. Nesse movimento, as ações e práticas em saúde constituem-se em esforços para superar uma atuação especializada e fragmentada e avançar numa proposta de tra- balho em equipe multiprofissional que organiza o pensar e o fazer com enfoque interdisciplinar. Somam-se a esse esforço as tentativas de romper com a organização macroestrutural dos serviços de saúde que determina, no nível micro, uma prática que atende à produtividade e a procedimentos profissional-centrados em detrimento da produção de projetos terapêuticos usuário-centrados.

Ao pensar sobre a formação do profissional de saúde, consideramos pertinente reportar-nos ao entendimento de que o processo educativo deveria extrapolar o domínio técnico-científico da profissão e estender-se aos aspetos estruturantes das relações e das práticas com relevância social contribuindo com a qualidade de saúde da população ${ }^{(16)}$. Assim, a formação profissional não pode ter como referência apenas a doença, o processo diagnóstico e o tratamento, mas deve possibilitar uma compreensão ampliada das necessidades de saúde, com vistas a desenvolver ações voltadas para a integralidade do cuidado.

Essa análise incide, também, na aproximação a um projeto de ensino-aprendizagem que incorpore os conhecimentos das ciências biológicas, humanas, das relações interpessoais, sociais e do meio ambiente. Sobretudo na apropriação de concepções pedagógicas e de metodologias que permitam a construção e reconstrução permanente das habilidades e competências para um agir na gestão das ações dos serviços de saúde, considerando a diversidade, a imprevisibilidade e a complexidade do setor e que seja centrado no ser cuidado com suas demandas, necessidades e direitos.

Se, defendemos que é necessário construir uma rede ensino-serviço, admitimos que é primordial mudar as relações entre os distintos atores sinalizando para o compartilhamento de saberes numa construção coletiva em que as situações do agir em saúde tornam-se motes para o processo ensino-aprendizagem. Trabalha-se então com o agir em saúde como um fator de exposição dos alunos aos problemas reais da prática, o que só se faz em contextos nos quais as instituições de ensino e serviço dialogam, negociam e estabelecem parcerias $^{(2)}$. Ao mesmo tempo, essas novas relações ressignificam as práticas educativas e mudam a compreensão da construção do conhecimento potencializando a relação: reflexão sobre a realidade / teorização / ação / reflexão, nos cenários de produção do agir em saúde.

\section{CONSIDERAÇÕES FINAIS}

Abordar a orientação da formação do enfermeiro para a integralidade da atenção à saúde, constitui objeto de estudo necessário na identificação das necessidades de mudanças e das potencialidades no desenvolvimento do ensino de enfermagem, que garantam uma formação profissional voltada ao reconhecimento e afirmação dos princípios do SUS. 
Nesse movimento, a formação do enfermeiro apresenta uma trajetória de mudança que sinaliza a construção da integralidade do cuidado na saúde. Essa construção é revelada como um processo de superação da relação dialética entre os enfoques individual e coletivo para uma possibilidade que considera a (inter)subjetividade nas práticas em saúde.

É enfática a referência à aplicação das tecnologias leves em saúde, na análise dos dados, como importantes momentos de escuta, de criação de vínculos e valorização das subjetividades, da singularidade, das relações afetivas, da espiritualidade. Entretanto, o trabalho em saúde apresenta-se sustentado em um modelo de caráter positivista, prevalecendo uma forma de organização dos serviços sustentada na atenção curativa, reforçando a medicalização e o atendimento aos sintomas biológicos, a qual não é coerente com o objeto e a finalidade do trabalho na perspectiva da integralidade do cuidado na saúde.

Ressalta-se que essa construção é um movimento de redefinição de saberes e práticas nos serviços de saúde, superando a visão de organização hierarquizada que tem por finalidade atender às demandas em saúde, para uma organização em rede de cuidados que permitam a ampliação da autonomia e co-responsabilidade do sujeito por sua saúde e por seu modo de vida. Nesse processo, assinala-se o projeto terapêutico em articulação com os conhecimentos da Clínica, da Epidemiologia, da Saúde Coletiva e também da antropologia, da psicologia, da organização político-econômica e outros que se façam necessários, para construir a possibilidade do cuidado centrado no usuário. Vê-se que esses saberes e fazeres se recompõem tendo como ênfase as tecnologias leves em saúde, expressas no diálogo, nas auscultas, no relacionamento ético e na criação de vínculos.

Fica claro que a construção de vínculos nas relações entre profissionais e usuário é um desafio para a integralidade do cuidado. Aponta-se como desafio, também, a criação de dispositivos na superação de um modelo que tem centralidade no ato dos profissionais e com pouca visibilidade das ações de promoção da saúde para construir a possibilidade do cuidado centrado no usuário. Para se construir uma prática pautada na inte-gralidade, os profissionais de saúde devem estar capacitados para responder ao sofrimento manifesto dos indivíduos, atendendo a demanda espontânea e, de modo articulado, oferecer ações e/ou procedimentos preventivos. Tal perspectiva deve ser defendida em toda a cadeia de cuidados, ou seja, todos os serviços devem se ocupar tanto da promoção e da prevenção quanto da assistência curativa.

Embora se reconheça, as limitações do estudo de caso para possíveis generalizações no campo da pesquisa qualitativa, considera-se fundamental tomar os resultados do estudo na reflexão sobre a formação dos enfermeiros. É importante considerar que a construção da integralidade é um movimento que se faz no cotidiano das práticas em saúde e, como tal, interfere nas micropolíticas do trabalho em saúde.

Construir a integralidade do cuidado em saúde implica assumir o agir em saúde como princípio educativo em uma nova forma de aprender/ensinar em saúde, que rompe com o saber formatado e descontextualizado. Significa, também, estabelecer uma prática de saúde entendendo o processo saúde-doença e o ser humano inserido nesse processo influenciado por valores, crenças, determinações políticas, econômicas e sociais.

Ao mesmo tempo, é preciso construir, nos modelos de ensino dos profissionais de saúde, práticas pedagógicas que permitam a compreensão da integralidade como um pressuposto que precisa ser construído durante toda a formação. Para tanto, a educação precisa ser também integral e interdisciplinar, com base em referenciais críticoreflexivos, permitindo a aquisição de competências e habilidades que assegurem um agir voltado para o ser humano na sua subjetividade.

\section{REFERÊNCIAS}

1. Assad MAC. A interdisciplinaridade na área de saúde da Universidade Estadual de Londrina: análise de um programa [dissertação]. Londrina: Universidade Estadual de Londrina; 1999.

2. Silva KL, Sena RR. A formação do enfermeiro: construindo a integralidade do cuidado. Rev Bras Enferm. 2006; 59(4):488-91.

3. Brasil. Ministério da Educação e Cultura. Conselho Nacional de Educação. Diretrizes Curriculares Nacionais do Curso de Graduação em Enfermagem. Diário Oficial da União, Brasília, 9 nov. 2001. Seção 1, p. 37.
4. Fernandes JD, Xavier IM, Ceribelli MIPF, Bianco MHC, Maeda D, Rodrigues MVC. Diretrizes curriculares e estratégias para implantação de uma nova proposta pedagógica. Rev Esc Enferm USP. 2005;39(4):443-9.

5. Ito EE, Peres AM, Takahashi RT, Leite MMJ. O ensino de enfermagem e as diretrizes curriculares nacionais: utopia $x$ realidade. Rev Esc Enferm USP. 2006;40(4):570-5.

6. Mattos RA. A integralidade na prática (ou sobre a prática da integralidade). Cad Saúde Pública. 2004; 20 (5): 1411-6. 
7. Minayo MCS. Hermenêutica-dialética como caminho do pensamento social. In: Minayo MCS, Deslandes SF, organizadores. Caminhos do pensamento: epistemologia e método. Rio de Janeiro: FIOCRUZ; 2002. p. 83-107.

8. Guareschi P. Alteridade e relação: uma perspectiva crítica. In: Arruda A. Representando a alteridade. Petrópolis: Vozes; 1998. p. 149-61.

9. Mendes Gonçalves RB. Práticas de saúde: processos de trabalho e necessidades. São Paulo: SMS-SP/Centro de Formação dos Trabalhadores da Saúde; 1992.

10. Leopardi MT. Necessidades de saúde e cidadania. Texto Contexto Enferm. 1992;1(1):54-73.

11. Cecílio LCO. As necessidades de saúde como conceito estruturante na luta pela integralidade e equidade na atenção em saúde. In: Pinheiro R, Mattos RA. Os sentidos da integralidade na atenção e no cuidado à saúde. Rio de Janeiro: Ed. UERJ; 2001. p. 113-26.

12. Merhy EE. A perda da dimensão cuidadora na produção da saúde: discussão do modelo assistencial e da intervenção no seu modo de trabalhar a assistência. In: Reis AT, organizador. Sistema Único de Saúde em Belo Horizonte: reescrevendo o público. São Paulo: Xamã; 1998. p. 103-20.

13. Nascimento MAA. O ensino da Saúde Coletiva na formação dos profissionais de enfermagem. J ABEn. 2003; 45(4):14-5.

14. Merhy EE. Em busca de ferramentas analisadoras das tecnologias em saúde: a informação e o dia a dia de um serviço, interrogando e gerindo trabalho em saúde. In: Merhy EE, Onocko R, organizadores. Agir em saúde: um desafio para o público. 2a ed. São Paulo: Hucitec; 2002. p. $113-60$.
15. Merhy EE. Em busca da qualidade dos serviços de saúde: os serviços de porta aberta para a saúde e o modelo tecno-assistencial em defesa da vida (ou como aproveitar os ruídos do cotidiano dos serviços de saúde e colegiadamente reorganizar o processo de trabalho na busca da qualidade das ações de saúde). In: Cecílio LCO. Inventando a mudança na saúde. São Paulo: Hucitec; 1994. p. 117-60.

16. Silva KL, Sena RR. Nursing education: seeking criticalreflexive education and professional competencies. Rev Lat Am Enferm.2006;14(5):755-61.

17. Lück H. Pedagogia interdisciplinar. Petrópolis: Vozes; 2000.

18. Lacerda A, Valla VV. As práticas terapêuticas de cuidado integral à saúde como proposta para aliviar o sofrimento. In: Pinheiro R, Mattos RA. Cuidado: as fronteiras da integralidade. São Paulo: Hucitec; 2004. p. 91-102.

19. Silva Junior A, Merhy EE, Carvalho LC. Refletindo sobre o ato de cuidar da saúde. In: Pinheiro R, Mattos RA. A construção da integralidade: cotidiano, saberes e práticas em saúde. Rio de Janeiro: Ed. UERJ; 2003. p. 113-28.

20. Franco TB, Merhy EE. A produção imaginária da demanda e o processo de trabalho em saúde. In: Pinheiro $R$, Mattos RA. Construção social da demanda: direito á saúde, trabalho em equipe, participação e espaços públicos. Rio de Janeiro: Ed. UERJ; 2005. p. 181-94. 